\title{
Field Evaluation of 64 Rootstocks for Growth and Yield of 'Kensington Pride' Mango
}

\author{
Malcolm W. Smith ${ }^{1}$, Jeremy D. Bright ${ }^{2}$, Mark D. Hoult ${ }^{3,4}$, \\ Richard A. Renfree, and Tony Maddern \\ Katherine Research Station, Northern Territory Department of Primary \\ Industry, Fisheries and Mines, Katherine 0851, Australia
}

\section{Neil Coombes \\ Wagga Wagga Agricultural Institute, NSW Department of Primary Industry, Wagga Wagga 2650, Australia}

Additional index words. Mangifera indica, canopy silhouette area, tree size, yield efficiency, autotetraploid

\begin{abstract}
Despite an abundance of polyembryonic genotypes and the need for rootstocks that improve scion yield and productivity, simultaneous field testing of a wide range of mango (Mangifera indica $L$.) genotypes as rootstocks has not previously been reported. In this experiment, we examined the growth and yield of 'Kensington Pride' on 64 mango genotypes of diverse origin during the first four seasons of fruit production to identify those worth longer-term assessment. We also recorded morphological characteristics of seedlings of 46 of these genotypes in an attempt to relate these measures to subsequent field performance. Tree canopy development on the most vigorous rootstocks was almost double that on the least vigorous. Growth rates differed by more than $160 \%$. Cumulative marketable yield ranged from $36 \mathrm{~kg} /$ tree for the lowest yielding rootstock to $181 \mathrm{~kg} /$ tree for the most productive. Yield efficiency also differed markedly among the 64 rootstocks with the best treatment being 3.5 times more efficient than the poorest treatment. No relationship was found between yield efficiency and tree size, suggesting it is possible to select highly efficient rootstocks of differing vigor. Two genotypes ('Brodie' and 'MYP') stood out as providing high yield efficiency with small tree size. A further two genotypes ('B' and 'Watertank') were identified as offering high yield efficiency and large tree size and should provide high early yields at traditional tree spacing. Efforts to relate the morphology of different genotype seedlings to subsequent performance as a rootstock showed that nursery performance of mango seedlings is no indication of their likely behavior as a rootstock. The economic cost of poor yields and low yield efficiencies during the early years of commercial orchard production provide a rationale for culling many of the rootstock treatments in this experiment and concentrating future assessment on the top $\approx 20 \%$ of the 64 treatments. Of these, 'MYP', 'B', 'Watertank', 'Manzano', and 'Pancho' currently show the most promise.
\end{abstract}

Mango is grown in more than 80 countries throughout the tropics and subtropics with total annual production of $\approx 30$ million tons (FAO, 2008). With few exceptions, commercial yields are low compared with other fruit crops, seldom exceeding $10 \mathrm{t} \cdot \mathrm{ha}^{-1}$. Further-

Received for publication 12 May 2008. Accepted for publication 7 July 2008.

We thank Niranjan Dasari for his support during the establishment and conduct of this research and are indebted to Ian Baker for his foresight in expanding the germplasm collections from which seed was sourced for this work.

${ }^{1}$ Current address: Queensland Department of Primary Industries and Fisheries, 49 Ashfield Road, Bundaberg 4670, Australia.

${ }^{2}$ Current address: NSW Department of Primary Industries, Forest Road, Orange 2800, Australia.

${ }^{3}$ Current address: Berrimah Research Farm, Northern Territory Department of Primary Industry, Fisheries and Mines, Darwin 0801, Australia.

${ }^{4}$ To whom reprint requests should be addressed; e-mailmark.hoult@nt.gov.au under 'Kensington Pride' that differed in yield by $141 \%$. Rootstock effects on tree size have been of similar magnitude.

Although there is clear evidence that rootstocks can improve yield and yield efficiency in mango, all experiments to date have one limitation in common: they examine only a small number of genotypes ( 10 or fewer) as potential rootstocks. This is despite the availability of a diverse range of polyembryonic cultivars that could be used as rootstocks. High costs and the length of time needed are significant obstacles to large-scale field evaluations and point to early screening techniques as a possible way of improving the efficiency of mango rootstock research. The lack of large-scale rootstock experiments may partly explain why the modern mango industry lags behind crops such as apple, in which selection of an appropriate rootstock is as important to the success of a new orchard as the choice of the scion variety (Russo et al., 2007).

The objective of this work was to simultaneously evaluate the growth and yield of 'Kensington Pride' scion grafted onto 64 different mango genotypes. Field performance in the first 4 years of cropping is described and compared with the morphological characteristics of the original rootstock seedlings in the nursery in an attempt to develop early screening techniques.

\section{Materials and Methods}

Mango accessions in the Northern Territory (N.T.) germplasm collections (Berrimah Research Farm, Coast Plains Research Station, Katherine Research Station), together with material from a private collection (Mr. Ken Rayner) and morphologically distinct individual trees in the Katherine township, were assessed in Nov. 1995 to determine whether the seed type was mono- or polyembryonic. Seed was collected from the 63 genotypes that proved to be polyembryonic together with seed from the monoembryonic cultivar Glenn. The scion cultivar used in the experiment, Kensington Pride, is polyembryonic and seed of it was included as a rootstock to serve as a control combination. All seed was sown in individual 5-L pots. In Jan. 1996, the resulting seedlings were side veneergrafted (at $200 \mathrm{~mm}$ height) with 'Kensington Pride' budwood taken from a single tree that had shown consistently superior performance. In Feb. 1996, the rootstock seedlings were assessed for a range of morphological characters immediately before the rootstock was cut back to the graft stick. Characters assessed were seedling height, trunk diameter, stem and leaf dry weight, leaf area per plant, average leaf size and dry weight, internode length, bark thickness, bark percentage, and wood and bark density.

Grafted trees were field-planted in Apr. 1996 at a spacing of $8 \mathrm{~m}$ within the row and $10 \mathrm{~m}$ between rows in a commercial mango orchard near Katherine, N.T., Australia (lat. $14.483^{\circ} \mathrm{S}$, long. $132.239^{\circ} \mathrm{E}$ ). This region has a semiarid tropical climate with an intense 
wet season (average $972 \mathrm{~mm}$ per year) from December to February followed by a distinct dry period for most of the remaining months. The soil was a Ferric, Petroferric, Red Kandosol (loamy, Typic Alfisol) with free drainage throughout the profile. The soil had a $\mathrm{pH}$ of 8 and an electrical conductivity of less than $0.05 \mathrm{dS} \cdot \mathrm{m}^{-1}$. Trees were managed according to standard commercial practices (Crane et al., 1997), including monthly foliar nutrient applications during the first 18 months of tree establishment. Structural pruning ensured all trees developed three layers of three to four scaffolding branches each 0.5 to $1 \mathrm{~m}$ in length. Once this tree structure was established, no further pruning took place other than skirting of canopies to prevent fruit touching the ground.

Treatments were arranged within the first five replicates of the balanced lattice design for 64 treatments, Plan 10.5 of Cochran and Cox (1957), to form a valid partially balanced lattice square. Partially balanced lattice designs are standard incomplete block designs, which ensure pairs of treatments occur together in blocks as equally as possible. The blocks of the lattice were arranged in $4 \times 2$ tree blocks across pairs of rows of the design. Treatments were randomized within blocks to improve neighbor balance properties. The experiment consisted of 320 trees (five single-tree replicates of 64 treatments) and was guarded on all sides. Data were analyzed using the REML directive in GenStat (Genstat 9; Lawes Agricultural Trust, Rothamsted, UK) fitting replicate and lattice block as random effects.

Trunk circumference was measured at 12 monthly intervals at both a distance of 100 $\mathrm{mm}$ above and $100 \mathrm{~mm}$ below the graft union and converted to trunk cross-sectional areas (TCA). A linear regression of TCA (below the graft union) against time from planting was fitted for each tree. The resulting slope of this regression line was then used as a measure of the growth rate of each tree (Littell, 1989). Tree canopy size was measured at the end of the fourth season's harvest when trees had been in the field for 5 years 8 months. Digital capture and analysis methods were used and a projected canopy silhouette area (CSA) value obtained for each tree (Smith et al., 2003). The start of fruit harvesting in each season was determined by testing flesh dry matter content and normally occurred in mid-October. There were two harvests in 2000, three in 1998 and 2001, and four in 1999 with harvest events being 8 to $12 \mathrm{~d}$ apart. Marketable fruit number and weight were recorded at each harvest. Yield efficiency was determined by using TCA $\left(\mathrm{kg} \cdot \mathrm{cm}^{-2}\right.$ TCA) as well as CSA $\left(\mathrm{kg} \cdot \mathrm{m}^{-2}\right.$ CSA). Efficiency values based on TCA were calculated in each season using the corresponding trunk measurements for that season as well as for cumulative 4-year yield. An overall yield efficiency value was also calculated by dividing the cumulative 4 -year yield by the CSA value determined after the final harvest. A gross income (GI) was calculated for each tree to take account of the interaction between yield, fruit size and earliness, and the economic advantage of high yields of large fruit produced early in the season. To calculate GI, each tree's yield at each harvest date was multiplied by the market price for that size fruit and the results summed. A 7-d period was allowed between the harvest date and the market price (Wholesale Markets Sydney, Sydney, Australia) used in this calculation to allow for time from harvesting to selling. Results were summed for the four seasons to produce a gross dollar value for each tree.

\section{Results}

Tree growth. Measures of tree size and growth rate revealed large differences between the rootstock treatments (Table 1). 'Kurukan' produced the largest tree canopy $\left(\mathrm{CSA}=7.52 \mathrm{~m}^{-2}\right)$, whereas 'Vellaikulamban' was the smallest $\left(\mathrm{CSA}=4.16 \mathrm{~m}^{-2}\right)$. The small tree size of 'Vellaikulamban' was also reflected in its low growth rate $\left(4.91 \mathrm{~cm}^{-2}\right.$ TCA/month) in contrast with 'Orange', which produced the highest growth rate of $10.33 \mathrm{~cm}^{-2} \mathrm{TCA} / \mathrm{month}$. Trees with large CSA tended to have high TCA, although the correlations were always less than 0.7 , suggesting the need for caution in estimating tree size based solely on trunk measurements. Similarly, tree growth rates based on changes in TCA showed some discrepancies with CSA. For example, although 'Neil' and 'Rosa' had a similar CSA, the latter had a growth rate $66 \%$ higher than the former. Most rootstock genotypes produced graft unions in which the scion TCA was smaller than the rootstock TCA with only 10 treatments developing scion overgrowth, the most notable being 'Neil' (ratio of scion TCA:rootstock TCA $=1.12$ ). This effect was reversed, resulting in a distinct "benching" effect with rootstocks such as 'Kensington Pride' (0.69), 'Phoenix' (0.69), and 'Vellaikulamban' (0.73). However, these rootstock differences in graft union morphology were not related to any tree growth or yield differences and should not be used as a criterion for rootstock selection.

Fruit production. Rootstock had a significant effect on marketable yields in each of the four individual seasons (data not presented) as well as cumulatively (Table 2 ). On a cumulative basis, marketable fruit yield was highest on 'B' (181 kg/tree) and lowest on 'Chandrakaran' ( $36 \mathrm{~kg} /$ tree). In the third season, rootstocks differed more than eightfold between the highest and lowest yielding treatments, whereas in the fourth season, they differed more than fivefold. High-yielding rootstock treatments tended to perform consistently across the four seasons, although it is too early to be certain that these stocks have reduced biennial bearing. Yield efficiencies varied widely between different rootstocks (Table 2). Rootstocks that produced high yield efficiency on a CSA basis for cumulative yield tended to perform well when yield efficiency was expressed on a TCA basis in individual seasons. Similarly, rootstock treatments with low efficiency based on CSA for cumulative yield tended to perform poorly based on TCA in individual seasons. Rootstocks with high yield efficiency included 'MYP', 'B', 'Manzano', 'Brodie', 'Pancho', 'Starch', and 'Watertank'. These rootstocks are some of the most promising and warrant further assessment. Among the least yield efficient rootstocks were 'Pico', 'Tong Dum', and 'Muvandan'.

Significant rootstock effects on average fruit size were detected in the second and third seasons of cropping but not in the first or fourth. When average fruit size was calculated for cumulative production, rootstock effects were not significant (data not presented). Gross income per tree was highest for 'B' ( $\$ 569 /$ tree) and lowest for 'Chandrakaran' (\$104/tree) (Table 2).

There was no relationship between tree size (CSA) and yield efficiency for the 64 rootstocks $\left(r^{2}=0.008\right)$ (Fig. 1). However, the scatterplot clearly demonstrates the opportunity to select highly efficient rootstocks of differing vigor. For example, 'B', 'MYP', and 'Brodie' had similarly high yield efficiencies but differed markedly in canopy size.

Nursery versus field performance. Our attempts to correlate the 12 morphological characteristics of nursery seedlings and subsequent field performance characteristics (tree size, yield, yield efficiency, and average fruit size) revealed no significant relationships between nursery and field variables. The strongest correlation $(-0.32)$ was between bark percentage and cumulative yield, suggesting that genotypes where the bark occupies a larger percentage of the trunk diameter tended to produce low yields when used as rootstocks. However, the relationship is too weak to be of value in screening germplasm.

\section{Discussion}

This experiment has identified a subset of genotypes with high yield and productivity worthy of longer-term evaluation. The magnitude of differences between the best and worst treatments is substantially higher than in previous rootstock research and points to the importance of screening a large number of genotypes of diverse origin in the search for superior rootstocks for mango. Furthermore, the poor performance of most genotypes in this experiment, compared with rootstocks currently in local commercial use (mainly 'Kensington Pride'), illustrates the financial dangers of using rootstock genotypes that have not been adequately evaluated.

Results from previous mango rootstock experiments suggest that the highest yields (on a per-tree basis) are associated with the most vigorous rootstocks. However, in this experiment with a far larger range of genotypes, it becomes clear that rootstock vigor is not necessarily related to fruit production. For example, the rootstock 'Orange' produced very large trees with the highest growth rate and yet yielded nearly $50 \%$ less 
Table 1. Canopy silhouette area (CSA), trunk growth rate, and scion:rootstock girth ratio of 'Kensington Pride' mango field-grown for 5 years 8 months on 64 rootstocks of diverse origin.

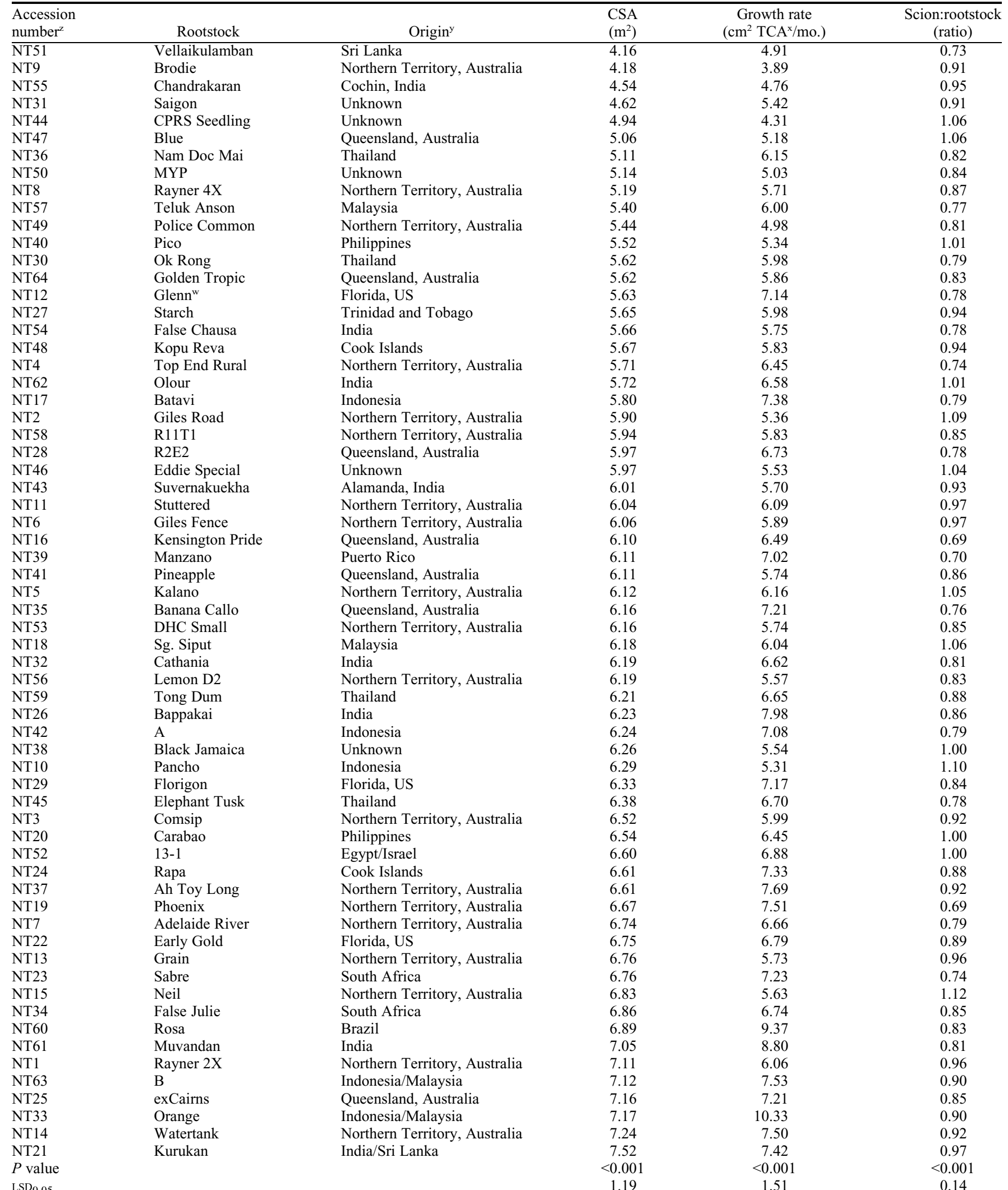

${ }^{\mathrm{z}}$ Unique code given to each individual accession in Northern Territory mango arboreta.

${ }^{y}$ Indicative only as a result of the complexity of tracing the true origin of mango germplasm.

${ }^{\mathrm{x}} \mathrm{TCA}=$ trunk cross-sectional area.

wThe only monoembryonic rootstock in the experiment.

LSD $=$ least significant difference. 
Table 2. Cumulative yield, yield efficiency [based on both canopy silhouette area (CSA) and trunk crosssectional areas (TCA)] and gross income of 'Kensington Pride' mango on 64 rootstocks in the first 4 years of cropping.

\begin{tabular}{|c|c|c|c|c|}
\hline \multirow[b]{2}{*}{ Rootstock } & \multirow{2}{*}{$\begin{array}{c}\text { Cumulative yield } \\
(\mathrm{kg} / \text { tree })\end{array}$} & \multicolumn{2}{|c|}{ Yield efficiency } & \multirow{2}{*}{$\begin{array}{c}\text { Gross income } \\
(\$ / \text { tree })\end{array}$} \\
\hline & & $\overline{\left(\mathrm{kg} \cdot \mathrm{m}^{-2} \mathrm{CSA}\right)}$ & $\overline{\left(\mathrm{kg} \cdot \mathrm{cm}^{-2} \mathrm{TCA}\right)}$ & \\
\hline$\overline{\mathrm{B}}$ & 181 & 26.1 & 0.485 & 569 \\
\hline Watertank & 165 & 23.0 & 0.385 & 510 \\
\hline Manzano & 159 & 26.0 & 0.397 & 490 \\
\hline Pancho & 155 & 25.5 & 0.500 & 476 \\
\hline MYP & 138 & 27.8 & 0.476 & 413 \\
\hline Phoenix & 137 & 21.1 & 0.315 & 411 \\
\hline Starch & 131 & 23.0 & 0.380 & 403 \\
\hline Stuttered & 130 & 22.0 & 0.436 & 397 \\
\hline Grain & 129 & 17.9 & 0.386 & 398 \\
\hline Kensington Pride & 128 & 21.5 & 0.376 & 385 \\
\hline Carabao & 124 & 19.3 & 0.364 & 375 \\
\hline $13-1$ & 122 & 18.8 & 0.364 & 370 \\
\hline Top End Rural & 120 & 20.6 & 0.325 & 367 \\
\hline Bappakai & 118 & 19.2 & 0.291 & 361 \\
\hline Sg. Siput & 116 & 19.5 & 0.349 & 354 \\
\hline Glenn & 115 & 20.6 & 0.337 & 363 \\
\hline Comsip & 113 & 17.2 & 0.360 & 338 \\
\hline False Julie & 113 & 16.1 & 0.301 & 344 \\
\hline Early Gold & 110 & 17.2 & 0.289 & 339 \\
\hline Brodie & 108 & 25.9 & 0.503 & 336 \\
\hline Kurukan & 106 & 14.1 & 0.280 & 314 \\
\hline Kopu Reva & 100 & 17.6 & 0.375 & 291 \\
\hline R2E2 & 99 & 16.3 & 0.273 & 301 \\
\hline Kalano & 98 & 16.4 & 0.307 & 294 \\
\hline Giles Road & 98 & 16.9 & 0.360 & 288 \\
\hline Rayner 2X & 98 & 14.1 & 0.296 & 285 \\
\hline Adelaide River & 97 & 14.6 & 0.266 & 306 \\
\hline exCairns & 96 & 13.2 & 0.267 & 292 \\
\hline Sabre & 96 & 13.3 & 0.209 & 286 \\
\hline Pineapple & 96 & 15.9 & 0.317 & 281 \\
\hline False Chausa & 95 & 17.2 & 0.346 & 282 \\
\hline Giles Fence & 95 & 16.0 & 0.308 & 278 \\
\hline Police Common & 93 & 17.4 & 0.400 & 280 \\
\hline Rapa & 90 & 13.0 & 0.223 & 276 \\
\hline Eddie Special & 90 & 15.3 & 0.339 & 265 \\
\hline Golden Tropic & 90 & 15.8 & 0.329 & 280 \\
\hline Neil & 88 & 13.4 & 0.290 & 259 \\
\hline Ah Toy Long & 87 & 13.5 & 0.221 & 272 \\
\hline Suvernakuekha & 87 & 13.4 & 0.312 & 263 \\
\hline Florigon & 86 & 13.3 & 0.243 & 267 \\
\hline Orange & 86 & 11.9 & 0.185 & 258 \\
\hline Ok Rong & 85 & 15.3 & 0.261 & 264 \\
\hline Lemon D2 & 85 & 15.1 & 0.330 & 248 \\
\hline A & 83 & 13.7 & 0.230 & 262 \\
\hline Vellaikulamban & 80 & 19.3 & 0.312 & 247 \\
\hline Batavi & 78 & 13.3 & 0.195 & 244 \\
\hline Rayner 4X & 78 & 15.9 & 0.272 & 227 \\
\hline DHC Small & 76 & 12.7 & 0.288 & 232 \\
\hline Saigon & 75 & 17.3 & 0.259 & 236 \\
\hline Black Jamaica & 75 & 12.0 & 0.305 & 227 \\
\hline Banana Callo & 75 & 12.1 & 0.214 & 231 \\
\hline Olour & 72 & 12.4 & 0.195 & 220 \\
\hline Cathania & 71 & 11.1 & 0.232 & 209 \\
\hline Rosa & 71 & 11.0 & 0.166 & 215 \\
\hline Teluk Anson & 69 & 13.1 & 0.243 & 205 \\
\hline R11T1 & 68 & 12.1 & 0.253 & 204 \\
\hline Muvandan & 66 & 9.2 & 0.149 & 203 \\
\hline Nam Doc Mai & 64 & 12.2 & 0.235 & 197 \\
\hline Elephant Tusk & 64 & 10.0 & 0.194 & 189 \\
\hline CPRS Seedling & 64 & 15.2 & 0.309 & 191 \\
\hline Tong Dum & 52 & 8.9 & 0.173 & 153 \\
\hline Blue & 51 & 10.1 & 0.227 & 157 \\
\hline Pico & 39 & 7.9 & 0.193 & 119 \\
\hline Chandrakaran & 36 & 9.4 & 0.174 & 104 \\
\hline$P$ value & $<0.001$ & $<0.001$ & $<0.001$ & $<0.001$ \\
\hline $\mathrm{LSD}_{0.05}$ & 43 & 7.3 & 0.122 & 135 \\
\hline
\end{tabular}

LSD $=$ least significant difference.

than some treatments. Conversely, 'MYP' produced some of the highest yields on some of the smallest trees. This diversity has important implications for different produc- tion systems in which it might be anticipated that low vigor stocks are needed in higherdensity plantings (Reddy et al., 2003) and more vigorous stocks for traditional spacing.
Wheaton et al. (1995) found that the economic viability of high-density plantings in citrus was dependent on the availability of lower vigor rootstocks. This might also be true for a terminal bearing tree crop like mango. In our experiment, the GI value of each rootstock was calculated from market price, fruit size, seasonal maturity time, and yields in each of the four seasons and showed a strong relationship with cumulative yield. However, this calculated income per tree does not account for crop management and harvest costs that may differ between rootstocks. For example, 'MYP' and 'Phoenix' gave a similar GI value, but the former was almost 30\% smaller in tree size and therefore would be cheaper to manage and harvest. Thus, a number of genotypes offer similar economic returns in terms of high yields of good-sized fruit at the right time of the season, but a subset of them may also lower orchard costs through reduced vegetative vigor.

The prospect of highly efficient rootstocks of differing vigor has particular implications for hot tropical environments such as the area used in this experiment, where managing vegetative vigor can be a major problem. Tree pruning in such environments has only a short-term effect in reducing tree size, stimulates excessive vegetative growth, and can reduce fruit production in subsequent seasons (Medina-Urrutia and Nuñez-Elisea, 1997). Highly efficient rootstocks of moderate vigor may reduce the frequency and intensity of pruning in hot tropical regions. Furthermore, the wide range of observed responses in terms of tree size, growth rates, and fruit production may offer future research opportunities to better understand the physiology of this lowyielding species. Rootstocks like 'Orange', 'Chandrakaran', 'B', and 'MYP' clearly differ in how they influence scion biomass accumulation as well as carbon allocation between vegetative and reproductive processes. Studying these stocks under a range of management practices, including pruning, may improve our understanding of carbon allocation between vegetative and reproductive growth and lead to better management practices.

Results from this experiment are somewhat different from those obtained previously with 'Kensington Pride' in this region (Smith et al., 2003). Principal among these differences has been the improved performance of 'Sabre' and 'Kensington Pride' and the mediocre performance of 'Sg Siput'. This may be the result of differences in soil type between the two experiments with the original experiment planted on a sandy soil and this most recent work planted on a clay loam. Evidence from other tree crops suggests that it is unlikely a single rootstock will perform well on all soil types, and although there is no known evidence of mango rootstocks differing in performance as a result of soil type (other than where salinity is an issue), our results illustrate the need to examine a range of improved rootstock genotypes 


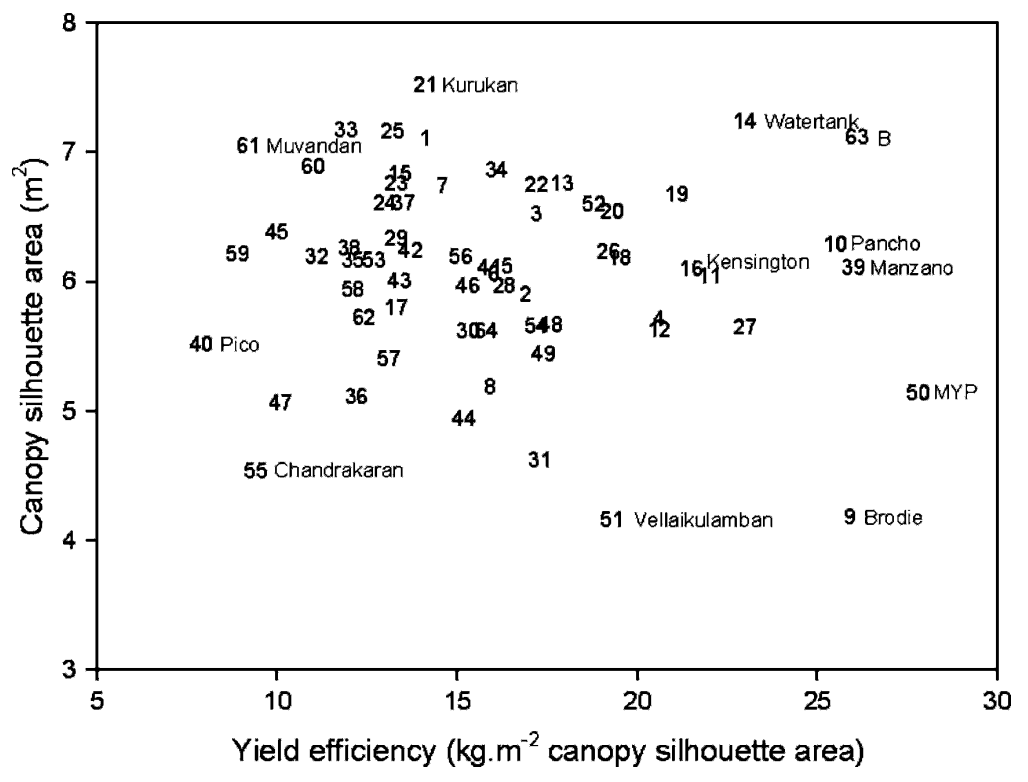

Fig. 1. Relationship between tree size (canopy silhouette area) and yield efficiency of 'Kensington Pride' mango on 64 rootstocks. Rootstock names of most interest are indicated following the plotted accession numbers (as per Table 1).

under various conditions to identify superior genotypes for commercial orchards.

Source arboretum trees of some of the 64 genotypes included in the experiment appeared morphologically indistinguishable but were included as separate treatments because of different origins and/or naming. Four such trees were 'Sg Siput', 'B', 'Eddie Special', and 'Pancho'. Results presented in this article show the performance of these four rootstocks to be quite disparate, contrary to what would be expected if they were an identical genotype. A similar situation exists with two of the most important rootstocks used for citrus. Troyer and Carrizo citrange are morphologically identical, some even arguing that they are the same genotype (Savage and Gardner, 1965), and yet they sometimes show important differences (e.g., nematode resistance, juice Brix) when used as rootstocks. In the case of mango rootstocks, our results suggest the need for caution in assuming that morphologically identical polyembryonic cultivars will behave similarly when used as rootstocks.

One of the longest running and most widely published mango rootstock experiments is in Bangalore, India [most recently described in Reddy et al. (2003)] in which eight rootstocks are being examined for their influence on 'Alphonso' performance. An early report on this experiment (Kohli and Reddy, 1989) stimulated efforts to introduce these genotypes into the N.T. germplasm collection. Seeds from these genotypes were thus available for our experiment with 'Kensington Pride'. As a consequence, we can now examine the comparative performance of a range of mango rootstocks with different scion varieties on two different continents. Reddy et al. (2003) found major rootstock effects on tree growth and vigor with 'Vellaikulamban' identified as imparting dwarfing. It was also found to give high yield efficiency. We also found that 'Vellaikulamban' reduced vigor with this cultivar giving the smallest canopy size and lowest growth rate of any of the 64 rootstocks. However, 'Kensington Pride' has yielded poorly on this rootstock, resulting in low yields per tree and low yield efficiency. Our results for other stocks examined in Bangalore are also generally consistent in terms of canopy size and development, but not in terms of fruit production. For example, Bangalore's highest yielding rootstock, 'Muvandan', is in our lowest $15 \%$ of treatments in terms of cumulative yield. Another Bangalore-recommended rootstock, 'Olour', also failed to show outstanding performance in our experiment. These discrepancies may be explained by different climatic/edaphic conditions and the intrinsic differences between the scion varieties 'Alphonso' and 'Kensington Pride'. For example, the highest yielding rootstock in our experiment produced $181 \mathrm{~kg} /$ tree within 6 years of planting, whereas in the experiment with 'Alphonso', this yield level was not reached on the best rootstock until the 14th year.

Galán Saúco et al. (2001) have demonstrated the occurrence of spontaneous chromosome doubling in apomictic mango cultivars, which results in tetraploid progeny morphologically distinct from their diploid progenitors. An identical phenomenon occurs within the Citrus genus and has long been recognized as a potential source of dwarfing rootstocks for this crop (Lee, 1988), although it has yet to achieve any commercial significance. The occurrence of these morphologically distinct mango plants in seed batches from polyembryonic cultivars was noted by an astute nurseryman at Katherine, N.T., in 1989. He grew some of these seedlings through to maturity and observed that the progeny of these trees also showed the same distinct morphology. Consequently, we were able to include this material ('Rayner
$4 X$ ') along with the original diploid progenitor ('Rayner $2 \mathrm{X}$ ') as two treatments in our rootstock experiment. Our preliminary results with mango indicate a reduction in canopy size associated with the tetraploid, although yield efficiency has not changed. Thus, there may be some value in developing and screening autotetraploids of superior mango rootstock genotypes in the hope of reducing vigor while retaining other superior characteristics.

The time and cost involved in long-term field experiments makes the prospect of predicting field performance from nursery seedling morphology a very attractive one. However, our results suggest that the morphology of seedlings bears little relationship to their subsequent performance as rootstocks. At this stage, there seems to be no alternative to field evaluation to identify the most promising rootstock genotypes.

The geographical origin of genotypes examined in this experiment seemed to play no clear role in their performance as rootstocks with the more promising genotypes coming from a range of countries, including Australia, India, Malaysia, Puerto Rico, and the United States. The early and widespread distribution of mango cultivars around the world makes the determination of the true botanical origin of this germplasm very difficult to establish, although it seems clear that in future screening work, it would be wise to examine polyembryonic genotypes from all continents where mangoes are grown.

This preliminary field screening of a diverse range of germplasm has demonstrated large differences in rootstock performance and the potential to select highly efficient genotypes with differing vigor. A subset of this material warrants longer-term assessment before commercialization.

\section{Literature Cited}

Cochran, W.G. and G.M. Cox. 1957. Experimental designs. Wiley, New York, NY.

Crane, J.H., I.S.E. Bally, R.V. Mosqueda-Vazquez, and E. Tomer. 1997. Crop production, p. 203 256. In: Litz, R.E. (ed.). The mango: Botany, production and uses. CAB Intl., Wallingford, UK.

FAO. 2008. FAOSTAT agricultural data. $30 \mathrm{Feb}$. 2008. <http://faostat.fao.org/site/567/Desktop Default.aspx?PageID $=567>$.

Galán Saúco, V., M.J. Grajal Martín, D. Fernández Galván, Á. Coello Torres, J. Juárez, and L. Navarro. 2001. Occurrence of spontaneous tetraploid nucellar mango plants. HortScience 36:755-757

Kohli, R.R. and Y.T.N. Reddy. 1989. Influence of rootstocks on growth, yield and leaf nutrient composition of Alphonso mango. Acta Hort. 231:225-231.

Lee, L.S. 1988. Citrus polyploidy-Origins and potential for cultivar improvement. Austral. J. Agr. Res. 39:735-747.

Littell, R.C. 1989. Statistical analysis of experiments with repeated measurements. HortScience 24:37-40.

Medina-Urrutia, V.M. and R. Nuñez-Elisea. 1997. Mechanical pruning to control tree size, 
flowering, and yield of mature 'Tommy Atkins' mango trees. Acta Hort. 455:305314.

Ngo, H. and G. Owens. 2002. The profitability of mangoes in the Top End. Northern Territory Dept. Primary Ind. Tech. Bul. 301.

Reddy, Y.T.N., R.M. Kurian, P.R. Ramachander, S. Gorakh, and R.R. Kohli. 2003. Longterm effects of rootstocks on growth and fruit yielding patterns of 'Alphonso' mango
(Mangifera indica L.). Scientia Hort. 97:95108.

Russo, N.L., T.L. Robinson, G. Fazio, and H.S. Aldwinckle. 2007. Field evaluation of 64 apple rootstocks for orchard performance and fire blight resistance. HortScience 42:15171525.

Savage, E.M. and F.E. Gardner. 1965. The origin and history of Troyer and Carrizo citranges. Citrus Ind. 46:5-7.
Smith, M.W., M.D. Hoult, and J.D. Bright. 2003. Rootstock affects yield, yield efficiency, and harvest rate of 'Kensington Pride' mango. HortScience 38:273-276.

Wheaton, T.A., J.D. Whitney, W.S. Castle, R.P. Muraro, H.W. Browning, and D.P.H. Tucker. 1995. Citrus scion and rootstock, topping height and tree spacing affect tree size, yield fruit quality and economic return. J. Amer. Soc. Hort. Sci. 120:861-870. 